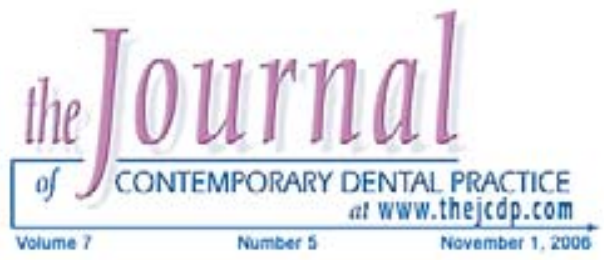

\title{
The Effect of Two Different Polishing Techniques on Microleakage of New Composites in Class V Restorations
}

\author{
Filiz Yalcin, DDS, PhD; Yonca Korkmaz, DDS, PhD; \\ Meserret Baseren, DDS, PhD
}

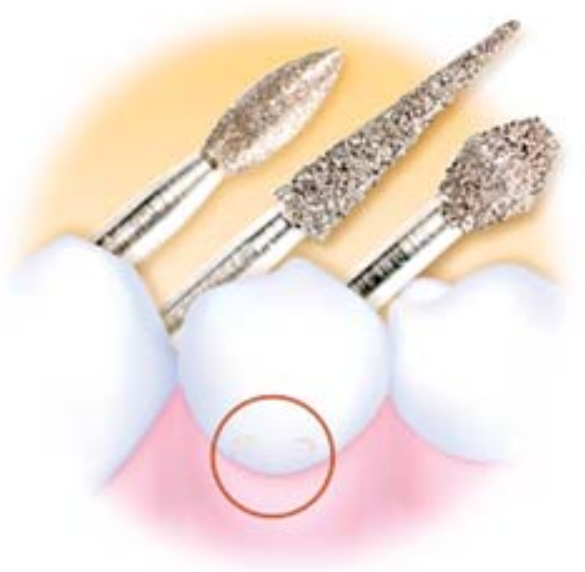

Abstract

Aim: The purpose of this study was to investigate the effect of polishing systems on the microleakage of a nanofill, a nanohybrid, and a microhybrid composite in Class $V$ cavities.

Methods and Materials: Preparations were made at the cemento-enamel junction (CEJ) of 36 extracted human premolars. The teeth were randomly divided into three groups and restored with new resin composites according to the manufacturers' instructions as follows: Group 1, Filtek Supreme \& Single Bond; Group 2, Grandio \& Solobond; and Group 3, Artemis \& Excite. The restorations were finished with diamond finishing burs. The restored/finished teeth were randomly divided into two groups and polished using the following systems: Super-Snap $\left(\mathrm{Al}_{2} \mathrm{O}_{2}\right.$ coated, abrasive disc system, fine grit, and extra fine grit) and Astropol/Astrobrush (silicon-based abrasive polisher point and polisher brush). All specimens were thermocycled 1000 times with a 10 second dwell time. They were immersed in $0.5 \%$ aqueous basic fuchsin dye for 24 hours and then sectioned buccal-lingual-longitudinally through the center of both restorations of each tooth and evaluated under a stereomicroscope at $30 \mathrm{X}$ magnification. The degree of dye penetration was quantified.

Result: No significant difference in leakage scores was observed in enamel margins ( $p=0.456$, Kruskall Wallis test), but dentin margins were significantly affected by the different polishing systems $(p=0.037$, Kruskall Wallis test). The lower leakage scores were recorded for Astropol/Astrobrush polishing systems. The nanofill

(C) Seer Publishing 
composite showed the least leakage among the test groups in this study. The most leakage was observed in nanohybrid composite resin ( $p<0.05$, Mann Whitney $U$ test).

Conclusions: Under the conditions of this in vitro study: the microleakage resistance of composites at enamel margins is not significantly affected by the different polishing systems; the lowest leakage scores were recorded for Astropol/Astrobrush polishing techniques in different types of composites; and the ranking of the composite materials from most to least leakage at the dentin margins according to polishing techniques was Grandio $>$ Artemis > Filtek Supreme.

Keywords: Polishing systems, microleakage, new composites

Citation: Yalcin F, Korkmaz Y, Bas,eren M. The Effect of Two Different Polishing Techniques on Microleakage of New Composites in Class V Restorations. J Contemp Dent Pract 2006 November;(7)5:018-025.

\section{Introduction}

The formulations of composite resins have been improving for use in adhesive dentistry. In recent years nanofill and nanohybrid composites have been produced with innovative nanotechnology resulting in new microhybrid composites being available now in the dental marketplace. Nanotechnology offers the opportunity for designing restorative materials with new characteristics. The advent of these new composite materials containing finer filler particles permits these restorative materials to be polished to a higher degree. ${ }^{1}$

The effectiveness of finishing and polishing procedures on composite surfaces is an important consideration in the restorative process. High quality finishing and polishing improves both esthetics and longevity of composite restorations; whereas rough, poorly polished surfaces contribute to staining, plaque accumulation, gingival irritation, recurrent caries, and discoloration of the restoration. In adhesive restorations it is important to determine the best finishing/polishing technique to get the best results. ${ }^{2-5}$

A wide variety of finishing and polishing devices are available to the clinician including diamond and carbide burs, abrasive impregnated rubber cups and points, abrasive discs, strips, and polishing pastes. Variations in finishing/polishing systems for different types of composites have been shown to affect microleakage. ${ }^{6-9}$

According to $\mathrm{Kidd}^{10}$ microleakage is defined as the passage of bacteria, fluids, molecules, or ions between a cavity wall and the restorative

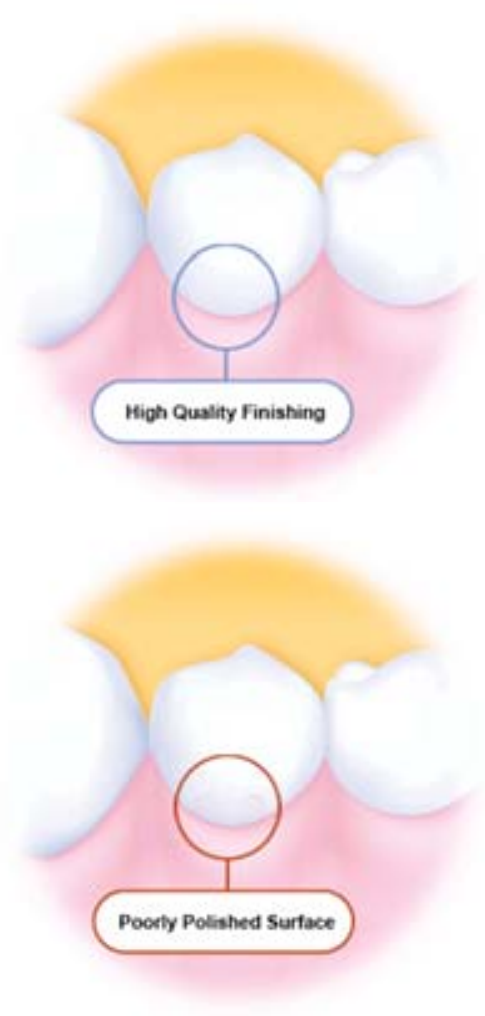

material. Microleakage can lead to staining, post operative sensitivity, and/or recurrent caries. ${ }^{9}$ Since these conditions may shorten the longevity of a restoration they should be mimimized or preferably eliminated. ${ }^{11-14}$

No study has been published on the influence of polishing techniques on the marginal leakage of nanofill or nanohybride composites. The aim of this study was to evaluate the effects of two different polishing systems on the microleakage of a nanofill, a nanohybrid, and a new microhybrid composite. 
Methods and Materials

Thirty-six freshly extracted human premolars without decay, cracks, or previous restorations were selected for the study. Calculi and residual soft tissue were removed carefully, and the teeth were stored at room temperature $\left(23^{\circ} \mathrm{C}-27^{\circ} \mathrm{C}\right)$ in distilled water for one month. Standard Class $\checkmark$ cavities (mesio-distal width of $3 \mathrm{~mm}$, occlusogingival length of $2 \mathrm{~mm}$, and a depth of $2 \mathrm{~mm}$ ) were prepared with a high-speed diamond flat end cylinder bur (835-010-4 ML, Diatech Dental AG, CH- 9435 Heerbrugg, Switzerland) using water as a coolant. The bur was changed after every fifth preparation. All the cavities with the occlusal margin in the enamel and the gingival margin in dentin were prepared on the buccal and palatal surfaces. All groups were restored with resin composites using the manufacturer's recommended dentin adhesives. The 36 teeth were randomly divided into three groups of 12 teeth (24 preparations) as follows:

- Group 1: Filtek Supreme / nanofill composite \& Single Bond (3M Dental Products, St. Paul, MN 55144, USA)

- Group 2: Grandio / nanohybrid composite \& Solobond M (Voco, Cuxhaven, Germany)

- Group 3: Artemis / microhybrid composite \& Excite (Vivadent, Ivoclar, Schaan, Liechtenstein).
Table 1 and Figure 1 shows the restorative materials used in this study.

The cavity preparations were restored using the following protocol. The entire preparation was etched with $37 \%$ phosphoric acid. The enamel was etched for 20 seconds with the dentin etched for 15 seconds. The cavities were rinsed thoroughly for 15 seconds and dried to remove excess water but leaving the dentin visibly moist. The adhesives were applied homogeneously with a disposable brush tip to the entire cavity surface. Excess solvent was then removed with a gentle stream of mild air flow and light-cured using a visible light-curing unit (Hilux Expert, Benlioglu Dental, Ankara, Turkey). Before use, the curing light was tested with a curing radiometer and found to have an output of $600 \mathrm{~mW} / \mathrm{cm}^{2}$; which was considered adequate. The preparations were then bulk filled with composite which were polymerized for 40 seconds.

All preparations, etching, bonding and restoration procedures were conducted by the same clinician in order to reduce variability. All restorations were finished after 24 hours using a series of diamond finishing burs (835-008-3 Diatech Dental AG, Heerbrugg, Switzerland) in a high-speed handpiece with water coolant. A new diamond

Table 1. Characteristics of restorative materials used in the study (manufacturers' data).

\begin{tabular}{|c|c|c|c|c|c|}
\hline $\begin{array}{l}\text { Restorative } \\
\text { Materials }\end{array}$ & Manufacturer & Matrix & Filler Size in $\mu$ & $\begin{array}{l}\text { Filler } \\
\text { Degree } \\
(\% \text { w/w })\end{array}$ & $\begin{array}{c}\text { Method of } \\
\text { Polymerization }\end{array}$ \\
\hline $\begin{array}{l}\text { Grandio } \\
\text { (Nanohybrid) }\end{array}$ & $\begin{array}{l}\text { Voco, Cuxhaven } \\
\text { GERMANY }\end{array}$ & $\begin{array}{l}\text { Bis-GMA, Urethane } \\
\text { Dimethacrylate, } \\
\text { Triethyleneglycol } \\
\text { Dimethacrylate }\end{array}$ & $\begin{array}{l}\text { Glass-ceramic } \\
\text { (microfiller) } 1 \mu \mathrm{m} \mathrm{SiO}, \\
\text { (nanofiller) } 20-60 \mathrm{~nm} .\end{array}$ & 87 & $\begin{array}{l}\text { Visible light } \\
\text { (Halogen) }\end{array}$ \\
\hline $\begin{array}{l}\text { Filtek Supreme } \\
\text { (Nanofili) }\end{array}$ & $\begin{array}{l}\text { 3M Dental } \\
\text { Products } \\
\text { St. Paul, MN } \\
\text { USA }\end{array}$ & $\begin{array}{l}\text { Triethyleneglycol } \\
\text { Dimethacrylate Urethane } \\
\text { Dimethacrylate, Bis-EMA, } \\
\text { Bis-GMA }\end{array}$ & $\begin{array}{l}\text { Zirconica-Silica } \\
\text { (microfiller) 0.6-1.4 } \mu \mathrm{m} \\
\text { silica }\end{array}$ & 78.5 & $\begin{array}{l}\text { Visible light } \\
\text { (Halogen) }\end{array}$ \\
\hline $\begin{array}{l}\text { Artemis } \\
\text { (Microhybrid) }\end{array}$ & Vivadent Schaan & $\begin{array}{l}\text { Urethane Dimethacrylate, } \\
\text { Triethyleneglycol }\end{array}$ & Ba-Al Fluorsilicate & $75-77$ & \\
\hline
\end{tabular}




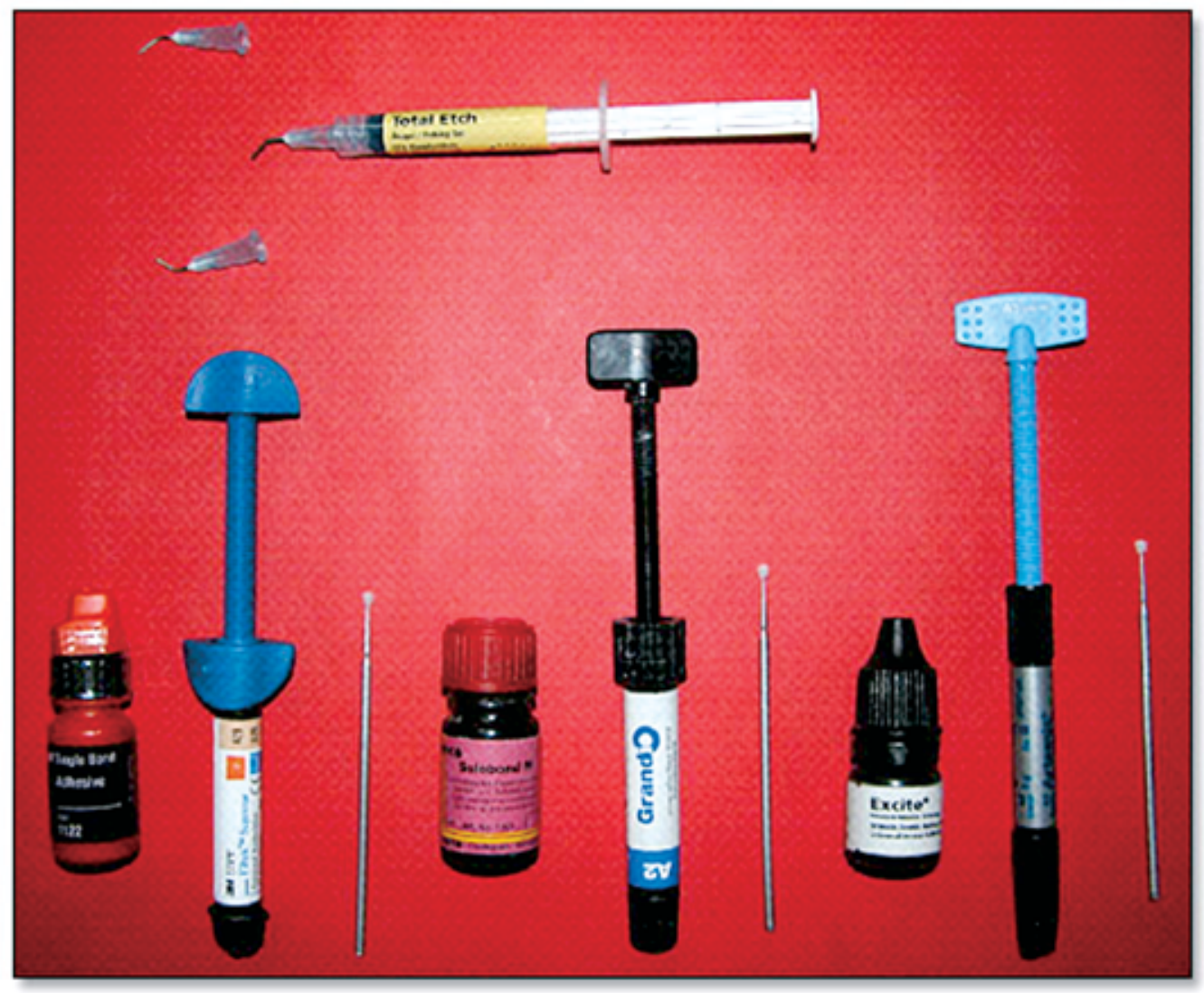

Figure 1. Restorative materials used in this study.

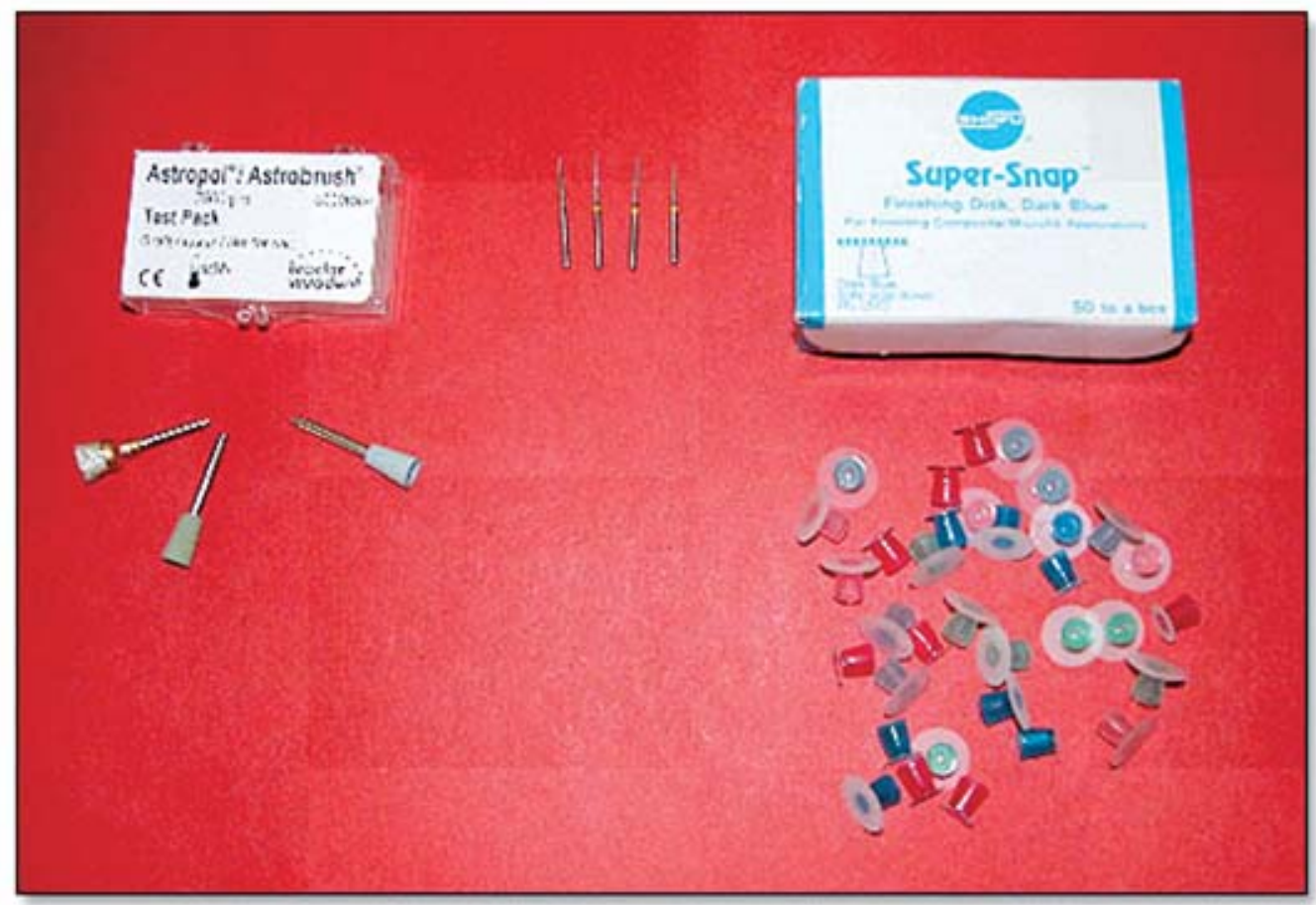

Figure 2. Finishing and polishing systems used in the study. 
bur was used for every fifth restoration. The three groups of restored/finished teeth were randomly subdivided into two groups and polished using the following systems: (1) Super-Snap Rainbow Technique Kit containing an $\mathrm{Al}_{2} \mathrm{O}_{2}$-coated abrasive disk system with fine grit and extra fine grit disks (Shofu Dental Corp, 4025 Bohannon Drive Menlo Park, CA, USA) and (2) the Astropol/ Astrobrush polishing system, a silicon-based abrasive polisher point and polisher brush system (Vivadent, Ivoclar, Schaan, Liechtenstein). Aluminium-oxide discs and silicone-based polisher points were used in a low-speed hand-piece with water spray. Each disk and silicone-based points were discarded after use (Figure 2).

The specimens were then thermocycled 1000 times with an exposure time of 2 seconds each at $5^{\circ} \mathrm{C}$ and $55^{\circ} \mathrm{C}$ and a dwell time of 10 seconds in a resting bath at $34^{\circ} \mathrm{C} .{ }^{15}$ The specimens were subsequently sealed with a composite resin (TPH Spectrum, Dentsply de Tray, Constanz, Germany) at the root apices, and two coats of nail varnish were applied on the tooth $1.5 \mathrm{~mm}$ short of the margins to be exposed to dye. The restorations were then immersed in $0.5 \%$ aqueous basic fuchsin dye for 24 hours. They subsequently were rinsed under running water to remove dye and dried at room temperature.
The specimens were sectioned longitudinally through the center of the restorations with a diamond saw (Isomed, Buehler, Ltd, Lake Bluff, IL, USA). Dye penetration was quantified for the enamel and dentin margins separately. The degree of dye penetration was then graded at 30X magnification with a stereomicroscope (Nikon SE, Nikon, Tokyo, Japan) using the scale described below. A 0-3 scoring system was used to describe the severity of infiltration:

$0=$ No dye penetration

$1=$ Dye penetration up to one-third of the cavity wall

2 = Dye penetration more than one-third, but less than two-thirds of the cavity wall

$3=$ Dye penetration more than two-thirds up to the entire cavity wall ${ }^{22}$

The linear microleakage scores for the groups were analyzed using a Kruskal-Wallis test and a Mann-Whitney $U$ test with a Bonferroni correction for pair wise multiple comparisons at a significance level of $p<0.05$.

\section{Results}

Table 2 shows the distribution of dye penetration scores at enamel and dentin margins in all six groups. For teeth restored with nanofill,

Table 2. Microleakage and mean leakage scores.

\begin{tabular}{|l|l|c|c|c|c|c|}
\hline \multicolumn{2}{|c|}{ Groups } & \multicolumn{5}{c|}{ Leakage Scores } \\
\cline { 3 - 7 } & $\mathbf{0}$ & $\mathbf{1}$ & $\mathbf{2}$ & $\mathbf{3}$ & Mean \\
\hline \multirow{2}{*}{ Filtek Supreme Super-Snap } & Enamel & 13 & 2 & 1 & 0 & 0.18 \\
\cline { 2 - 7 } & Dentin & 10 & 2 & 0 & 4 & 0.87 \\
\hline $\begin{array}{l}\text { Filtek Supreme Astropol- } \\
\text { Astrobrush }\end{array}$ & Enamel & 14 & 1 & 0 & 1 & 0.25 \\
\cline { 2 - 7 } & Dentin & 13 & 2 & 0 & 1 & 0.31 \\
\hline \multirow{2}{*}{ Grandio Super-Snap } & Enamel & 11 & 0 & 0 & 5 & 0.93 \\
\cline { 2 - 7 } & Dentin & 6 & 1 & 0 & 9 & 1.75 \\
\hline \multirow{2}{*}{ Grandio Astropol-Astrobrush } & Enamel & 11 & 2 & 0 & 3 & 0.68 \\
\cline { 2 - 7 } & Dentin & 11 & 2 & 0 & 3 & 0.68 \\
\hline \multirow{2}{*}{ Artemis Super-Snap } & Enamel & 16 & 0 & 0 & 0 & 0 \\
\cline { 2 - 7 } & Dentin & 8 & 4 & 1 & 3 & 0.93 \\
\hline \multirow{2}{*}{ Artemis Astropol-Astrobrush } & Enamel & 12 & 3 & 0 & 1 & 0.37 \\
\cline { 2 - 7 } & Dentin & 9 & 5 & 0 & 2 & 0.68 \\
\hline
\end{tabular}


nanohybrid, and microhybrid composites no significant difference in dye penetration was observed at the enamel margins $(p=0.456$, Kruskal Wallis test). For margins on dentin, a significant difference in dye penetration related to the finishing/polishing protocol was discovered ( $p=0.037$ Kruskal Wallis test). Lower leakage scores were recorded for Astropol/ Astrobrush polishing systems on different types of composites $(p<0.05$, Mann Whitney $U$ with Bonferroni test). The most leakage occurred with nanohybrid composite resin (Grandio) using the Super-Snap polishing system. A comparison of composite materials polished with two different polishing systems revealed a ranking from most to least leakage at the dentin margins as follows: Grandio > Artemis > Filtek Supreme $(p<0.05$, Mann Whitney U test).

\section{Discussion}

Several newer filling materials with finer inorganic particles are produced by means of advanced technology (nanofill and nanohybrid composites). This has resulted in a more durable restoration that can be polished to a finer finish. In this study a nanofill, a nanohybrid (materials containing nanoparticle fillers), and a new microhybrid composite were the materials of choice.

Marginal gaps and internal voids exist between cavity walls and restorative materials when these materials are poorly adapted. Microleakage may result from many factors such as the extent of the marginal gap, polymerization shrinkage of materials used ${ }^{16}$ the degradation of the particular bonding or restorative material used, ${ }^{17}$ dissolution of linear or smear layers, ${ }^{18}$ and varying coefficients of thermal expansion for restorations. ${ }^{19}$ Microleakage via the toothrestoration interface may lead to marginal stain, postoperative sensitivity, recurrent caries, and possibly pulp damage..$^{20}$ It is clear prevention of microleakage is an important concern in restorative dentistry. ${ }^{21}$

Finishing refers to the gross contouring of restorations to obtain the desired anatomy. Polishing refers to the reduction of roughness and scratches created by finishing instruments. The two procedures are, however, interdependent and cannot be delineated from each other; hence, use of the term finishing/polishing. ${ }^{22}$ Proper finishing and polishing are critical clinical procedures that enhance esthetics and the longevity of dental restorations. $^{23}$

Variation in finishing/polishing techniques has been shown to affect leakage. This is likely due to the heat generated locally during the polishing process. Water-cooled diamond finishing burs were used in this study to minimize local frictional heat generation. This was supported by $\mathrm{Yu}$ and others ${ }^{24}$ who examined the effects of finishing techniques on microleakage and found increased leakage when dry finishing techniques were used. This suggests a poorer adaptation of the restoration margin.

Diamond and carbide burs are necessary for contouring anatomic structures and concave surfaces such as the buccal and lingual surface of premolar and molar teeth. Although diamond burs cause a greater degree of gouging, the gouges are not as deep as with carbide finishing burs and the finished restorations can be brought to a smoother polish. ${ }^{25}$ In this study water cooled diamond finishing was preferred for finishing composite. Finishing becomes more difficult because an undefined cavosurface line angle is created in the gingival sulcus.

The specimens were finished/polished after 24 hours in this study. This is in accordance with some authors who suggest final finishing should always be delayed for at least 24 hours when composites are used. ${ }^{26-29}$ If finishing is conducted immediately after composite placement, the material might be more readily subject to plastic deformation due to the heat generated during the finishing/polishing procedure as approximately $75 \%$ of light-polymerization occurs during the first ten minutes. The polymerization reaction continues for a 24-hour period if the restoration is immersed in water before finishing procedures. The resultant water absorption expansion will then partially, or totally compensate for contraction and enhance adaptation. ${ }^{26}$

Dye penetration was chosen for this study because it provided a simple relatively inexpensive quantitative and comparable method of evaluating various composite systems. ${ }^{9}$

The thermocycling regimen recommended by Longman and Pearson ${ }^{15}$ was adopted to better simulate the oral environment. This thermocycling 
regime used provided greater thermal stresses than would one with a longer dwell time at extreme temperature since the material will only reach thermal equilibrium in the resting bath during each cycle.

While enamel is almost exclusively an inorganic tissue, dentin is less mineralized and contains more moisture which can cause variations in adhesion. ${ }^{30}$ The better bond to enamel is probably due to its greater inorganic content and homogeneity from a morphological stand point. The better bond could explain the significantly better seal obtained at the enamel margins with different polishing techniques. Microleakage at the enamel/restorations interface has been practically eliminated since the introduction of acid etching by Buonocore in 1955, but the sealing of margins still remains a challenge.$^{31}$ In this study there was no significant difference in leakage scores at the enamel margins compared to dentin.

Composites consisting of small particle size results in a smooth polished surface in finished restorations and are an appropriate selection for restoring Class $V$ cervical lesions. ${ }^{5}$ As finishing and polishing techniques produce a smoother surface texture with these composites, lower microleakage scores may be expected. This study also determined nanofill composite exhibited significantly lower microleakage scores than the other composites.

\section{Conclusion}

Under the conditions of this in vitro study:

1. The microleakage resistance of composites at enamel margins is not significantly affected by the different polishing systems tested.

2. Lower leakage scores were recorded for Astropol/Astrobrush polishing techniques used on different types of composites.

3. The ranking of composite materials from most to least leakage at the dentin margins according to polishing techniques used was as follows: Grandio > Artemis > Filtek Supreme.

\section{Clinical Relevance}

The use of the Astropol/Astrobrush polishing system resulted in less microleakage as compared to Super-Snap polishing system in Class $V$ cavities of a new nanofill, a nanohybrid, and a microhybrid composite. Use of a nanofill composite might be preferred in order to reduce microleakage.

\section{References}

1. Baseren M. Surface roughness of nanofill and nanohybrid composite resin and ormocer-based tooth-colored restorative materials after several finishing and polishing procedures. J Biomater Appl 2004; 19(2): 121-134.

2. Gwinnett AJ, Baratieri LN, Monterio SJR, deAndrada MAC, Vieira LCC, Cardoso AC, Ritter AV. Esthetics: direct adhesive restoration on fractured anterior teeth. San Paulo Quintessence Books 1995, 397.

3. Yap AUJ, Ang HQ, Chong KC. Influence of finishing time on marginal sealing ability of new generation composite bonding systems. J Oral Rehabil 1998; 25: 871-876.

4. Wilder AD Jr, Swift EJ Jr, May KN Jr, Thompson JY, McDougal RA. Effect of finishing technique on the microleakage of resin modified glass ionomer restorative materials. J Dent 2000; 28: 367-373.

5. Lopes GC, Vieira LCC, Araujo E. Direct composite resin restorations: a review of some clinical procedures to achieve predictable results in posterior teeth. J Esthet Restorative Dent 2004; 16(1): 7-16.

6. Lutz F, Setcos JC, Phillips RW. New finishing instruments for composite resins. J Am Dent Assoc 1983; 107: 575-580.

7. Davidson CL, De Gee AJ, Feilzer A. The competition between the composite dentin bond strength and the polymerization contraction stress. J Dent Res 1984; 63(12): 1396-1399.

8. Hoelscher DC, Neme AM, Pink FE, Hughes PJ. The effect of three finishing systems on four esthetic restorative materials. Oper Dent 1998; 23: 193-201. 
9. Yap AUJ, Wong ML, Lim ACY. The effect of polishing systems on microleakage of tooth colored restoratives: Part 2 Composite and polyasid- modified composite resins. J Oral Rehabil 2000; 27 : 205-210.

10. Kidd EA. Microleakage: A review. J Dent 1976; 4(5): 199-206.

11. Bergenholtz G, Cox CF, Loesche WJ, Syed SA. Bacterial leakage around dental restorations: Its effect on the dental pulp. J Oral Pathol 1982; 11(6): 439-450.

12. Cox F. Microleakage related to restorative procedures. Proceed Fin Dent Soc 1992; 88 (Suppl 1): 83-93.

13. Demarco FF, Ramos OLV, Mota CS, Formolo E, Justino LM. Influence of different restorative techniques on mikroleakage in class II cavities with gingival wall in cementum. Oper Dent 2001; 26: 253-259.

14. Manhart J, Chen HY,Mehl A, Weber K, Hickel R. Marginal quality and microleakage of adhesive class $\mathrm{V}$ restorations. J Dent 2001; 29: 123-130.

15. Longman CM, Pearson GJ. Variations in tooth surface temperature in the oral cavity during fluid intake. Biomaterials 1987; 8: 411.

16. Eick JD, Welch FH. Polymerization shrinkage of posterior composite resins and its possible influence on postoperative sensitivity. Quintessence Int 1986; 17(2): 103-111.

17. Oilo G. Biodegratation of dental composites/glassionomer cements. Adv Dent Res 1992; 6: 50-54.

18. Fortin D, Swift EJ, Denehy GE, Reinhart JW. Bond strength and microleakage of current dentine adhesives. Dent Mater 1994; 10(4): 253-258.

19. Suzuki M, Jordan RE, Boksman L. Posterior composite resin restorative- clinical considerations In vanherie G\&Smith Dc (eds) Posterior Composite Resin Dental Restorative materials St Paul 3M Co Peter Szulc Publishing Co, Netherlands 1985, 455.

20. Brannstrom M. The cause of postrestorative sensitivity and its prevention. J Endodont 1986; 12(10): 475-481.

21. Chuang S-F, Liu J-K, Jin Y-T. Microleakage and internal voids in class II composite restorations with flowable composite linings. Oper Dent 2001; 26: 193-200.

22. Yap AUJ, Yap WY, Yeo EJC, Tan JWS, Ong DSB. Effects of finishing/polishing techniques on microleakage of resin-modified glass ionomer cement restorations. Oper Dent 2003; 28: 36-41.

23. Yap AUJ, Tan S, Teh TY. The effect of polishing systems on microleakage of tooth colored restoratives: Part 1. Conventional and resin-modified glass-ionomer cements. J Oral Rehabil 2000; 27: 117-123.

24. Yu XY, Wieczkowski G, Davis EL, Joynt RB. The influence of finishing technique on microleakage. J Esthet Dent 1990; 2: 142.

25. Kaplan BA, Goldstein GR, Vijayaraghavan, Nelson IK. The effect of three polishing systems on the surface roughness of four hybrid composites; a profilometric and scanning electron microscopy study. J Prosthet Dent 1996; 76: 34.

26. Lopes GC, Franke M, Maia PH. Effect of finishing time and techniques on marginal sealing ability of two composite restorative materials. J Prosthet Dent 2002; 88(1): 32-36.

27. Asmussen E. Clinical relevance of physical,chemical and bonding properties of composite resin. Oper Dent 1985; 10: 61-73.

28. Davidson CL, Duysters PP, De Lange C, Bausch JR. Structural changes in composite surface material after dry polishing. J Oral Rehabil 1981; 8: 431-439.

29. Craig RG, Power C. Restorative dental materials. 11 th ed. St. Louis : Mosby; 2001. p 670.

30. Eick JD, Gwinnett AJ, Pashley DH, Robinson SJ. Current concepts on adhesion to dentin. Critic Rew Oral Biol Med 1997; 8(3): 306-335.

31. Gordan VV, Vargas MA, Cobb DS, Denehy GE. Evaluation of acidic primers in microleakage of class 5 composite resin restorations. Oper Dent 1998; 23: 244-249. 
About the Authors

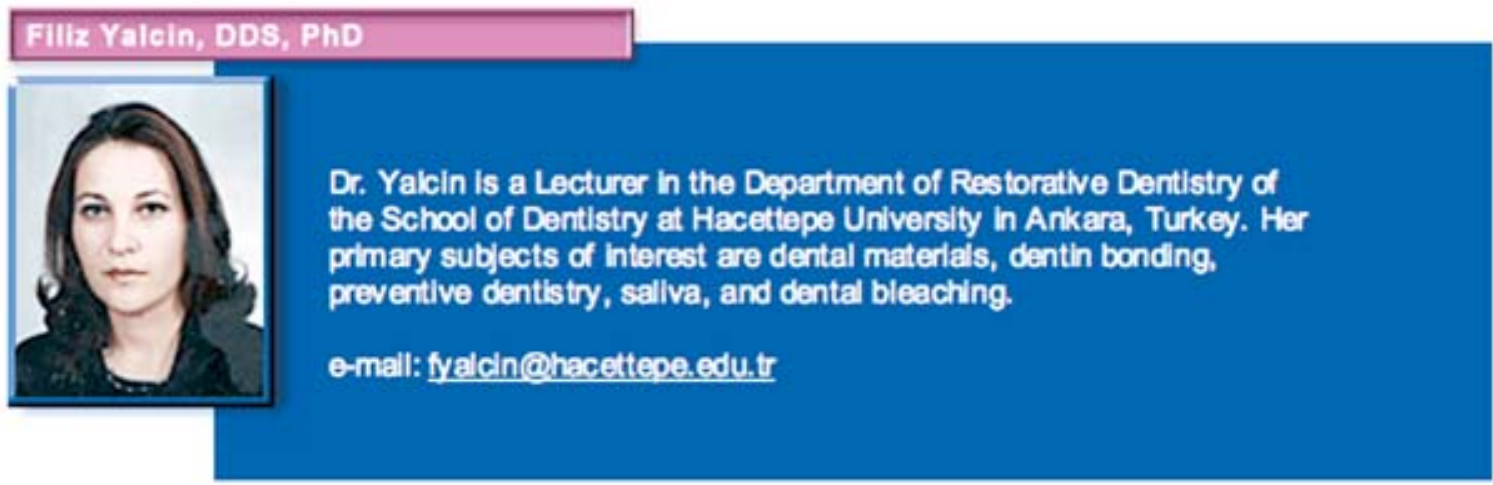

\section{Yonea Korkmaz, DDS, PhD}

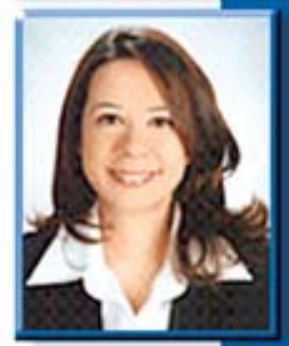

Dr. Korkmaz is a Research Assistant in the Department of Restorative Dentistry of the School of Dentistry at Hacettepe University in Ankara, Turkey. Her primary subjects of interest are dental materials, denth bonding, and root carles.

\section{Mosorrot Bagoron, DD8, PhD}

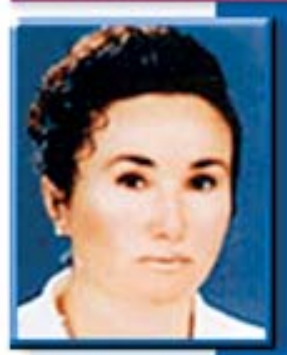

Dr. Baseren is a Professor in the Department of Restorative Dentistry of the School of Dentistry at Hacettepe University in Ankara, Turkey. Har primary subjects of interest are root carles, geriatric restorative dentistry, denth bonding, and preventive dentistry. 